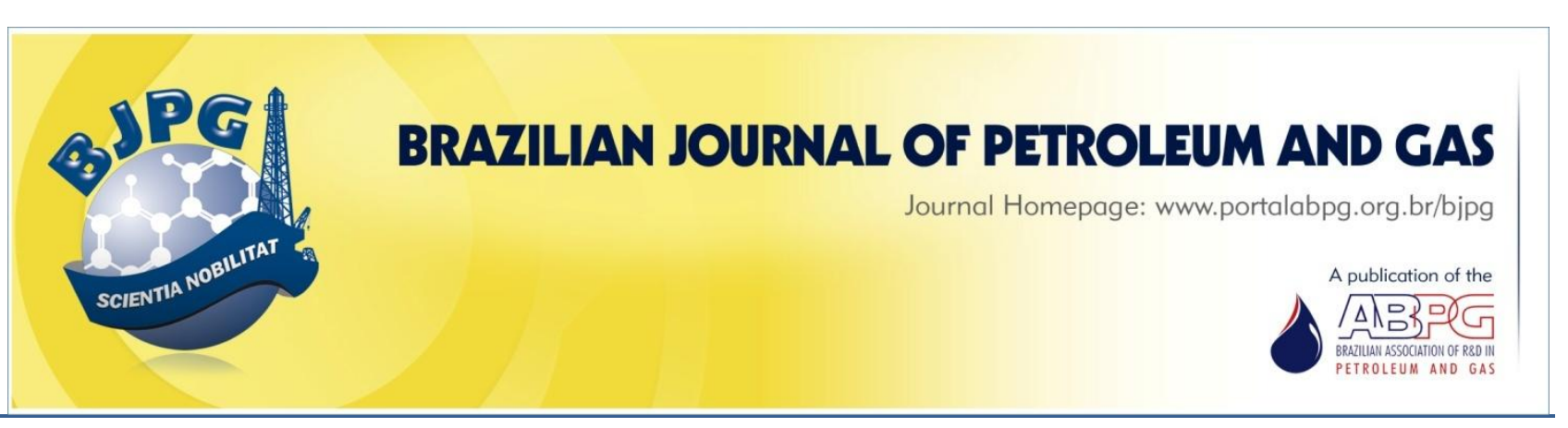

\title{
FINITE ELEMENT ANALYSIS APPLIED TO A METAL-TO-METAL SEAL DESIGN
}

\author{
${ }^{\text {a }}$ Lucci, B. N.; ${ }^{\text {b }}$ Lamas, W. Q. ${ }^{1} ;{ }^{\text {a }}$ Grandinetti, F. J.; ${ }^{\text {a }}$ Giacaglia, G. E. O. \\ a University of Taubaté, Department of Mechanical Engineering, Taubaté - SP, Brazil \\ ${ }^{b}$ University of São Paulo, Lorena School of Engineering, Department of Basic and Environmental Sciences, Lorena - SP, Brazil \\ Received: 20.04.2020 / Revised: 12.05.2020 / Accepted: 25.05.2020 / Published on line: 06.10 .2020
}

\begin{abstract}
This work presents the use of a finite element model software and suggests its use as a tool to develop metal-to-metal seals with the objective of reducing the number of designs and empirical tests, increasing possibility of success during validation tests, decreasing the number of repetitions of real tests needed, therefore, reducing execution costs. The present work configures a model of seal in a finite element analysis software and simulates different sizes of meshes to evaluate which configuration presented results and computational costs compatible with this work. Then, it develops different models in an interactive way, this is, it performs geometry changes with the intention of optimizing results. At the end of each model, it evaluates the results. This work develops and evaluates six models. At last, the authors selected the model which presented enough contact pressure to perform the sealing. This model presented a compatible stress in accordance with the failure criteria adopted, plastic strain in an acceptable range, and system behavior in accordance with that suggested by Sweeney, Brammer, and Chalmers (2004) in seal extremities.
\end{abstract}

\section{KEYWORDS}

finite element analysis; finite-element model; geometry seals design and test; metal-to-metal seal gasket; sub-sea equipment

\footnotetext{
${ }^{1}$ To whom all correspondence should be addressed.

Address: University of São Paulo (USP), Lorena School of Engineering, Department of Basic and Environmental Sciences, Estrada Municipal do Campinho, s/n, Ponte Nova, Lorena, SP, Brazil

ZIP Code: 12602-810 | e-mail: lamaswq@gmail.com

doi:10.5419/bjpg2020-0013
} 


\section{INTRODUCTION}

The sub-sea equipment used for oil and gas prospecting employs metal-to-metal seal gaskets to perform sealing between its components. In accordance with international standards established by the American Petroleum InstituteAPI (2010, 2011), metal-to-metal gaskets are qualified through specific validation tests to ensure their performance in different pressure work conditions. Figure 1 shows a well-head system as an example, where metal-to-metal seals are used to seal the system from the environment.

A well-head system is a system that connects the well to the seafloor. It ensures sealing between them, where system interfaces are sealed by metal-to metal seals.

Historically, these tests were performed using a "trial and error" method, where pre-dimensioning equipment, based in previous experiences, was projected by designer and, after that, qualification tests were performed. When test results did not present the expected performance, designers implemented small modifications in the same equipment, a new seal was manufactured, and the test was redone. This cycle was repeated until seal had passed in the qualification test.

This work proposes the utilization of specialized finite element analysis software with the intention to support stages of design, simulating qualification tests because of high costs of manufacturing, test execution, and re-design.

After the verification of the theoretical ideal design, the real qualification test would be performed, increasing the probability of success in test results. Using the methodology proposed, preliminary real tests could be replaced by computational simulations, reducing time and costs (Dassault Systèmes SIMULIA Corp., 2011). In Giner et al. (2009), it is possible to see an application of an extended finite element method with software ABAQUS $^{\odot}$. Also, Shi et al. (2010) presented this method applied to curvilinear metallic structures for fatigue crack growth and life prediction analyses.

Many researchers studied the physical characteristics of seals and gaskets. Abouel-Kasem (2006) investigated an evaluation method based on fracture onset to calculate elastomeric components



Figure 1. Example of a well-head system using a metal-to-metal seal (Drill-Quip, 2014).

lifetime. Bai and Bai (2019) analyzed sub-sea distribution systems describing major components and their gaskets. These authors also studied connections and jumpers used in sub-sea oil/gas production system, their seals and gaskets. They investigated sub-sea well-heads and Christmas trees, including seals and gaskets. Simulation techniques by Woo et al. (2014) introduced subsea production configuration processes and stable flow approach for fluids. Flitney (2014) discussed static seals and gaskets.

Studies also addressed mathematical modelling based on finite element analysis. Four types of finite element models were introduced by Kim, et al. (2007): a solid screw, a coupled screw, a spider screw, and a no-screw. A new von Mises elastoplasticity model combining linear isotropickinematic hardening was proposed by Kossa and Szabó (2010). Their study examined this method in detail, highlighting the use of software ABAQUS ${ }^{\odot}$.

Conduction of evaluation and stress-relaxation testing of elastomers were discussed by Slay and 
Webber (2011). A gasket model was developed by Haruyama et al. (2013). Their work also studied the flange surface roughness effect. Configurational concept forces was introduced in refinement of finite element mesh context for elastic-ideally problems by Hénap and Szabó (2014).

Economic engineering method for sub-sea equipment projects had been developed by Bai and Bai (2019) to estimate and maintain costs during a project, where accuracy range is $\pm 30 \%$ for sub-sea field.

The finite element model for casing wear mechanism research was established by $\mathrm{Yu}$ et al. (2016) using ABAQUS ${ }^{\odot}$ to study it in highly deviated well drilling. Also, the importance of sealing contact pressure research for sealing performance was discussed by Zhang et al. (2016) through fluid dynamics theory and finite element analyses of the sealing interface.

The mechanical model of micro-gap casing string of thermal production wells into heavy oil pipeline was divided into four intervals for further analyses by Chen et al. (2017), including the wellhead movement extension interval, the extension and compression movement interval between low-temperature zones, the packer movement interval, and the extension and compression movement interval between perforation sections. Cho et al. (2017) investigated bending characteristics of double-walled pipe during offshore sub-sea pipeline reel-lay operations using the finite element method. Rock mechanical experiments and numerical simulation experiments were carried out by Lin et al. (2017) to solve the problem of a large number of casing failures that occur during the volume fracturing operation of shale gas, making normal completion stimulations impossible.

The main objective of this work is to perform a study about utilization of software specialized in finite element analysis as a tool to support development of a metal-to-metal seal design.

The specific objective of this work is to propose a methodological cycle for design, analysis, redesign, and re-analysis until a satisfactory model to work in pre-determined conditions is achieved.

\section{MATERIALS AND METHODS}

\subsection{Finite element method}

The finite element method (FEM) goal is to determine stress and strain state from a solid with arbitrary geometry, subjected to external loads (Azevedo, 2003). The finite element is an approximated method to analyze continuous systems where structure, mechanical component, or, in general way, continuous body is subdivided in a finite number of parts, so-called elements, connected among them by discrete points, socalled nodes. The elements' composition consists of a mathematical model. The elements' behavior are specified by a finite number of parameters (Alves Filho, 2013). These parameters are formed by differential equations which are solved until obtaining expected results.

The FEM formulation requires an integral equation, so that is possible to replace integral under a complex domain of volume $V$ by a sum of integral extended to sub domains of simple geometry of volume $V_{\mathrm{i}}$. This technique is shown by the following example, corresponding to a volume integral for a function $f$ (Azevedo, 2003), Eq.(1).

$$
\int_{v} f d V=\sum_{i=1}^{n} \int_{v_{i}} f d V
$$

Eq. (1) presupposes that:

$$
V=\sum_{i=1}^{n} V_{i}
$$

If it is possible to calculate all extended integrals to sub domain $V_{i}$, it just executes correspondent sum to second member of Eq. (1) to obtain extended integral for all domain. Each sub-domain $V_{i}$ is correlated to one finite element of a simple geometry. The sum indicated in Eq. (1) will result in an operation called assembly (Azevedo, 2003).

There are several methods for numerical problem solving, but finite element analysis (FEA) provides the most accurate, versatile, and comprehensive way to solve complex design problems. Most design handbooks contain equations for the solution of simple geometry problems. As the geometry becomes more complex, the techniques and assumptions used in an attempt to simplify the problem either produce 
an equation that is obviously inapplicable, or impossible for the design engineer to solve. FEA allows the analysis of these complex structures without demanding the development and application of complex equations (Finney, 2012). Finite element analysis is a method, typically performed by software, used to create material models or designs to simulate stresses (Trelleborg Sealing Solutions- TSS, 2013). Finite element analysis is an effective method to acquire contact stress data (Hou et al., 2010).

A detailed seal model provides a comprehensive understanding of forces and stresses related to product or seal. A range of operational conditions, such as smooth or temperature and pressure variations or still dynamic hardware movement surrounding seal, can be calculated. Accounting for possibilities can be complex and it must be done on a case-by-case basis through human analyses and using the work of experienced operators (Trelleborg Sealing Solutions- TSS, 2013).

Finite element analysis (FEA) was used to determine optimal geometry for seal face and seat under given operating pressure, temperature, and speed conditions (Klier \& Schäfer, 2012).

Computer modelling uses design code to predict performance of seal designs prior to manufacture. Modern computers have contributed to advancement of seal technology more than any other tool. Mechanical seal manufacturers have developed state-of-the-art of modelling programs that allow designers to make changes to products and analyze their effects in a quick and efficient manner (Flach, 1995).

ABAQUS $^{\odot}$ 6.10-EF is a computational tool used to improve efficiency and accuracy of real-world performance of design simulations, including fluid leakage between 3-D bodies in contact and its mechanical capabilities (Flach, 1995).

A new design can be conceived, drawn up, and modelled by numerical computing with FEA support, and the tool makes it possible to determine results before any part is built. This method provides design iterations, shows results, and perhaps an optimum design prior to the construction of the proposed system. It also begins the tests necessary to compare empirical results with those evaluated through FEA, so that, later, a more predictable and cost-effective part can be developed in a timely fashion (Anderson, 1996).

\subsubsection{The von Mises stress}

Beyond checking contact pressure, the basic output for seal analysis, von Mises stress criteria is checked. This criterion is based in a determination of energy of distortion from a related material, that is, the energy related to changes in material form. By this criteria, a component will be in safe conditions until maximum energy value in distortion by a volume unit remains below distortion energy by a volume unit needed to perform material yield when submitted by a tensile test (Beer et al., 2014).

The von Mises stress $\left(\sigma^{\prime}\right)$ is calculated in accordance with the Eq. (3).

$$
\begin{gathered}
\sigma^{\prime}=\frac{1}{\sqrt{2}} \times\left[\left(\sigma_{x}-\sigma_{y}\right)^{2}+\left(\sigma_{y}-\sigma_{z}\right)^{2}+\left(\sigma_{z}-\sigma_{x}\right)^{2}\right. \\
\left.+6 \times\left(\tau_{x y}^{2}+\tau_{y z}^{2}+\tau_{z x}^{2}\right)\right]^{\frac{1}{2}}
\end{gathered}
$$

Where $\sigma_{x}, \sigma_{y}$, and $\sigma_{z}$ are normal stress in main axis and $\tau_{x y}, \tau_{y z}$, and $\tau_{z x}$ are shear stress in main planes (Jong \& Springer, 2009).

Figure 2 shows the comparison between von Mises and Tresca stress. Tresca stress criterion is a more conservative one. However, von Mises criterion presents values more accurate when considering ductile materials (Beer et al., 2014).

Figure 2 shows a comparison between Tresca and von Mises yielding failure criteria. It is possible to see the maximum allowable surface for each method. In accordance with each method, if a stress is applied inside the limits of surfaces, the material will work in an elastic phase. However, if a stress trespasses the limits of these surfaces, material will yield and work in a plastic phase.

\subsubsection{Permanent strain}

Structure deformation or strain degree depends on magnitude of imposed stress. For most metals that are stressed in tension and at relatively low levels, stress and strain are proportional to each other through their relationship as shown in Eq. (4).

$\sigma=E \cdot \varepsilon$

This is known as Hooke's law, where $\rho$ is stress, $E$ is proportionality constant or elasticity 


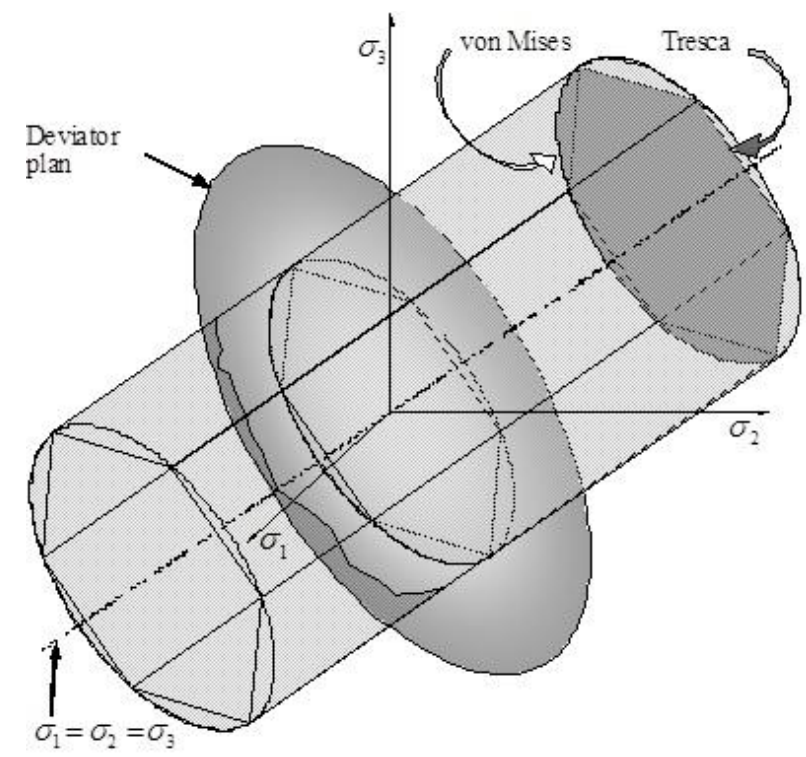

Figure 2. Graphic representation of yield surfaces for Tresca and Von Mises criteria (Natal Jorge \& Dinis, 2005).

modulus, and $\varepsilon$ is deformation (Callister Junior \& Rethwisch, 2009). Each material presents its own elasticity modulus.

Metallic materials typically show similar behaviour, as depicted in Figure 3.

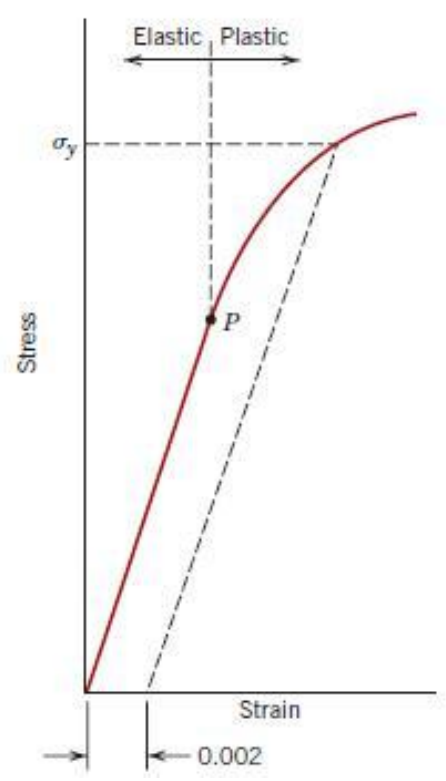

Figure 3. Typical stress-strain behaviour for metallic materials (Luebkeman \& Peting, 1996).

Figure 3 shows typical a stress-strain behavior of metallic materials. When a tension is applied until a value below point $P$, material works in an elastic phase, and after released stress, material recovers its original condition. If tension applied trespassing point $P$, material will show a permanent strain and will not recover initial condition.

\subsubsection{Contact pressure}

Hertz conducted the first satisfactory analysis of stresses at contact of two elastic solids (Johnson, 1987). Based on this theory, solutions for line contacts were developed by Johnson (1987). The formulas to calculate key contact details for both point and line contact are listed in Table 1 , where $E$ is elasticity modulus, $v$ is Poisson's ratio, $R$ is contact radius, and $w$ is applied load.

\subsection{Problem statement}

Main components of a metal-to-metal seal system are seal or gasket and seats (Figure 4). The development of a new seal starts when there is a demand to design sub-sea equipment and new conditions of work pressure are required, different bore sizes, and/or there is a new request of materials. In this specific case, the development of a new seal was requested with conditions in accordance with Table 2.

Elastic deformation occurs when stress and strain are proportional. From zero until point $P$, shown in Figure 4, material works in an elastic deformation, obeying Hooke's law. Material stress is not proportional to strain beyond this point, and permanent non-recoverable or plastic deformation occurs (Callister Junior \& Rethwisch, 2009). 
Table 1. Elastic contact formula for point and line contact (Bryant, 2013).

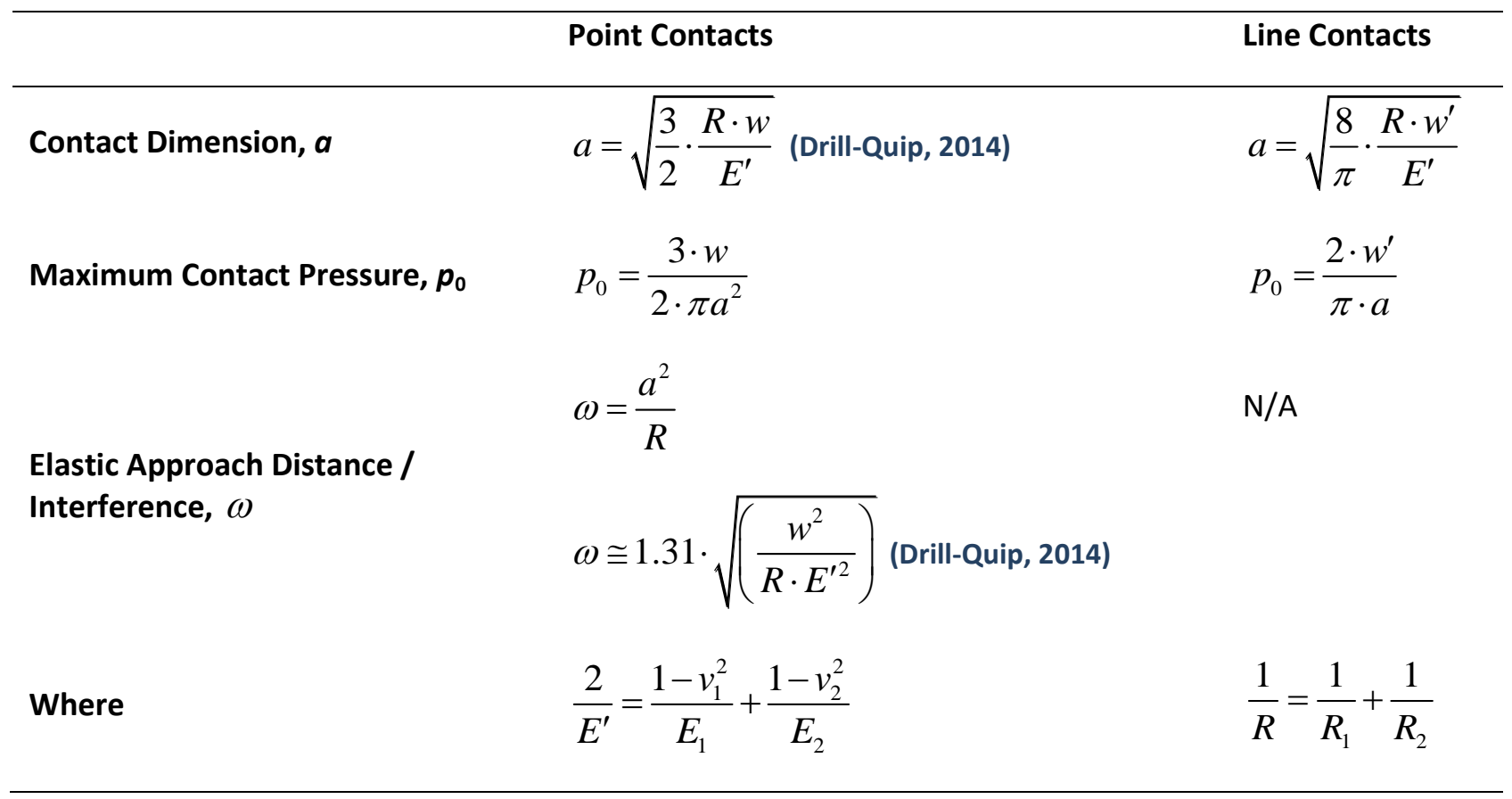

Table 2. Border conditions.

\begin{tabular}{ll}
\hline Description of condition & Value \\
\hline Internal maximum work pressure & $69 \mathrm{MPa}$ \\
Minimum internal bore & $130.17 \mathrm{~mm}(5.125 \mathrm{in})$ \\
\hline
\end{tabular}

New developments for oil and gas sub-sea equipment, generally, need for pressures to be at least $69 \mathrm{MPa}$. Internal bore in order of $130 \mathrm{~mm}$ is a

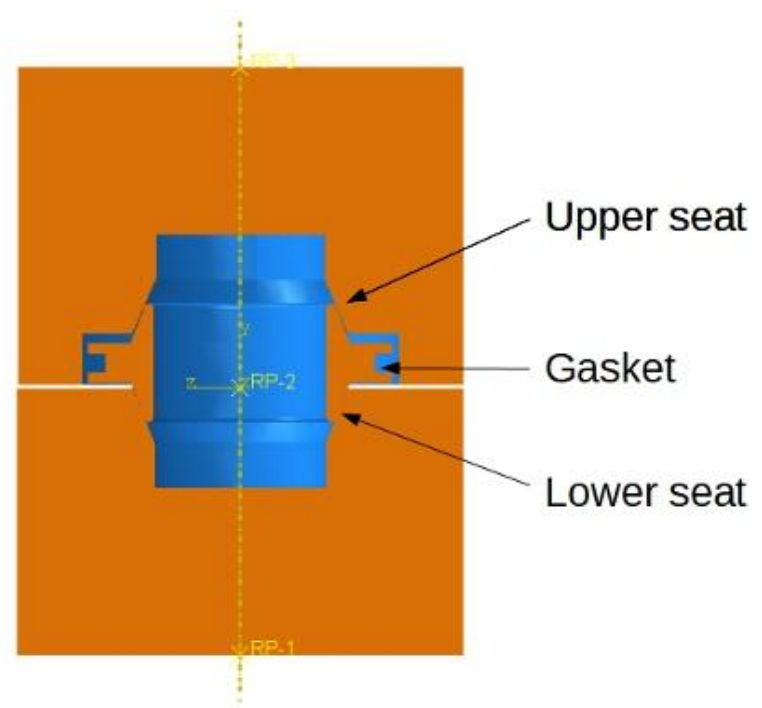

Figure 4. Main components of metal-to-metal seal system. common value used for sub-sea Christmas trees and production lines for related equipment.

Materials chosen for seat and seal for this work are described in Table 3 . These materials were chosen to be compatible with internal work fluids. Discussion of material is not part of this work.

Material properties for 625 alloy and 825 alloy are listed in Tables 4 and 5.

For the first model developed, we defined an energization course for the sealing system (Figure 5). In addition, differential angle between seal and seats was defined. Interferences and differential angle used are listed in Table 6.

The start differential angle was chosen empirically, following the recommendation from Sweeney et al. (2004). They described that the conical angle between seal and seat is, preferably, slightly different to create more contact stress in the sealing band. Energization course was chosen empirically (Figure 5). 
Table 3. Materials chosen.

\begin{tabular}{ll}
\hline Component & Material \\
\hline Gasket (seal) & 625 alloy \\
Seat & 825 alloy \\
\hline
\end{tabular}

Table 4. The 625 alloy properties (Special Metals Corporation, 2006).

\begin{tabular}{ll}
\hline Properties & Value \\
\hline $\begin{array}{l}\text { Modulus of } \\
\text { Elasticity }\end{array}$ & $207,500 \mathrm{MPa}$ \\
Poisson's Ratio & 0.278 \\
Yield Strength & $413.68 \mathrm{MPa}$ \\
Tensile Strength & $827.37 \mathrm{MPa}$ \\
\hline
\end{tabular}

Table 5. The 825 alloy properties (Special Metals Corporation, 2006).

\begin{tabular}{ll}
\hline Properties & Value \\
\hline Modulus of Elasticity & $\begin{array}{l}196,000 \\
\mathrm{MPa}\end{array}$ \\
Poisson's Ratio & 0.29 \\
Yield Strength & $324 \mathrm{MPa}$ \\
Tensile Strength & $690 \mathrm{MPa}$ \\
\hline
\end{tabular}

Table 6. Design parameters' changes for each model.

\begin{tabular}{lcc}
\hline Model & $\begin{array}{c}\text { Energisation } \\
\text { course }[\mathrm{mm}]\end{array}$ & $\begin{array}{c}\text { Differential } \\
\text { angle }\left[{ }^{\circ}\right]\end{array}$ \\
\hline First Model & 3.80 & 0.5 \\
Second Model & 3.80 & 1.0 \\
Third (Final) Model & 2.58 & 0.5 \\
\hline
\end{tabular}

A finite element model was created for each geometry proposed using the software ABAQUS ${ }^{\odot}$. ABAQUS Unified FEA suite ${ }^{\odot}$ offers powerful and complete solutions for both routine and sophisticated engineering problems, covering a vast spectrum of industrial applications (Dassault Systèmes, 2015).

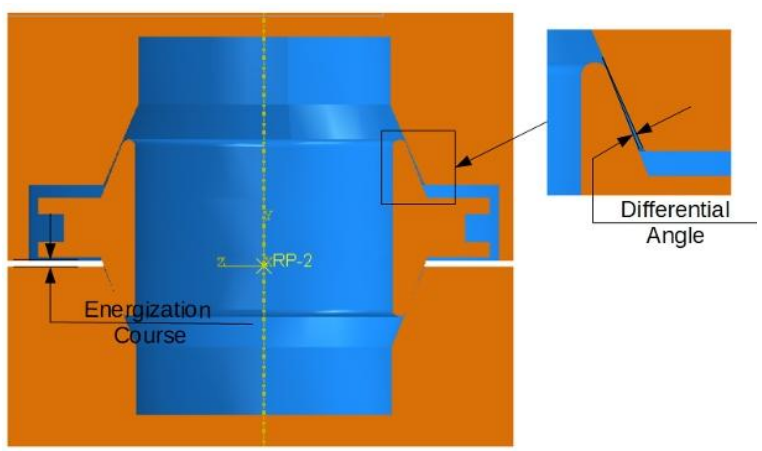

Figure 5. Energization course and differential angle of a metal-to-metal sealing system.

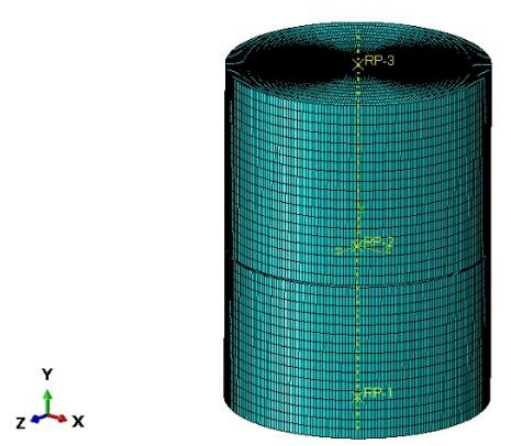

Figure 6. Mesh for the sealing system ( $3^{\text {rd }}$ model).

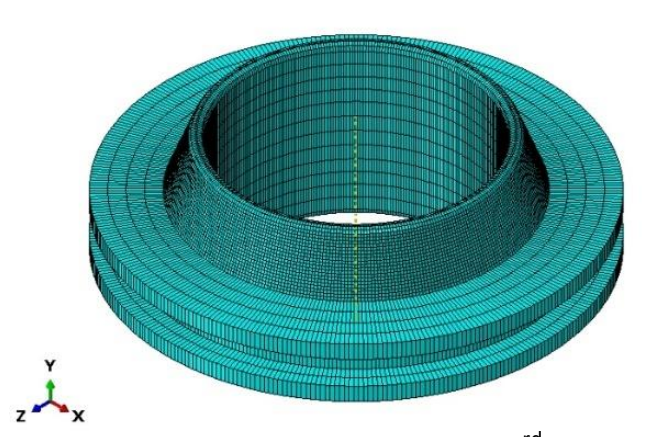

Figure 7. Mesh for the seal ( $3^{\text {rd }}$ model).

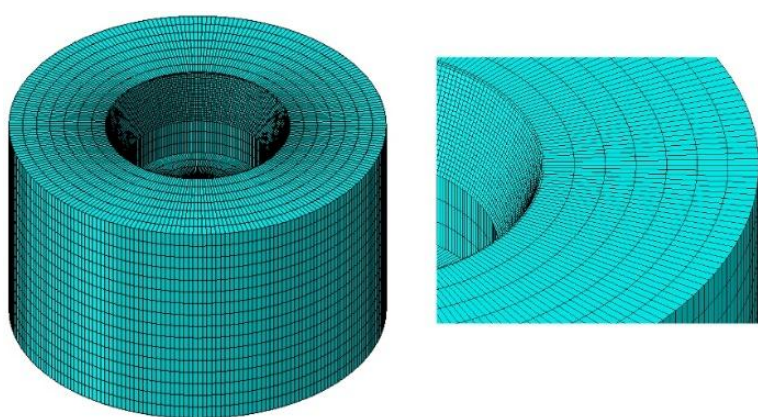

Figure 8. Mesh for the lower seat ( $3^{\text {rd }}$ model).

A similar mesh was created for each model. Figures 6, 7, and 8 show mesh for whole assembly, seal, and lower seat for the $3^{\text {rd }}$ model, respectively. Hexahedral elements were used to minimize 
Table 7. Number of nodes and elements for each model.

\begin{tabular}{lll}
\hline Model & Number of nodes & Number of elements \\
\hline First & 233,238 & 204,416 \\
Second & 215,980 & 187,488 \\
Third (Final) & 200,330 & 174,612 \\
\hline
\end{tabular}

distortion and achieve reliable results. In sealing areas of sealing system, mesh was refined. Table 7 lists number of nodes and elements used for each model.

Figure 6 shows general mesh used for the entire model.

Figure 7 shows the mesh for seal. Observing the image presented, is possible for one to find a high number of elements in sealing area of seal to achieve accurate results. This region is located sealing band and contact between seal and seat.

Figure 8 shows a mesh for the lower seat. Similar to Figure 7, on this image is possible to check a high number of elements in the sealing area of the lower seat.

Table 7 lists number of nodes and elements of each model. In this table, is possible to check how refined the mesh is for whole assembly.

The analysis was developed in two steps. The first step, displacement between seat was applied, with displacement defined in Table 6. In this step, contacts between seats and seal were created. The frictional coefficient considered was 0.15 . This value was found on Zhao (2011) for condition steel-steel static friction coefficient with no lubricant. At final stage of this step, one can anticipate that the seal will be deformed by seats to create a seal between surfaces.

Figure 9 shows where contact region for seal and upper seat was defined. The smaller region possible was defined to help a faster solving process. Similar to Figure 9, Figure 10 shows the contact region defined for seal and lower seat.

Figure 9 shows where contact regions between seal and upper seat were defined. The region in pink represents the contact region for the seat, while the red region constitutes the contact region for the seal.
Figure 10 shows where contact regions between seal and lower seat were defined. The region in pink represents the contact region for the seat while the red region constitutes the contact region for seal.

In the second step, an internal pressure of 69 $\mathrm{MPa}$ was applied to simulate internal working pressure, as listed in Table 2. Figure 11 shows the region where pressure was applied. The arrows represent where pressure was applied in second step.

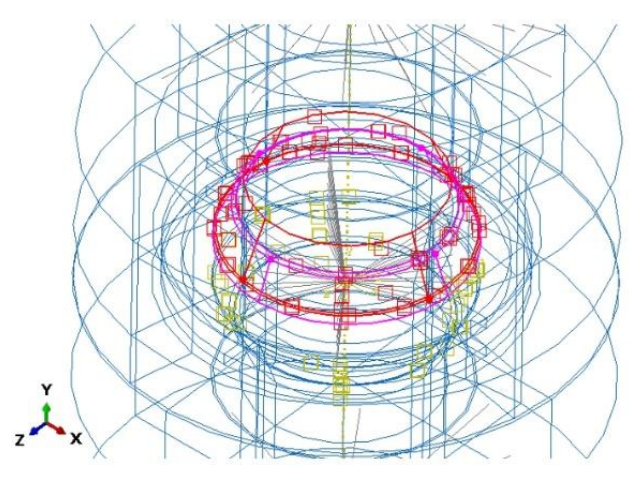

Figure 9. Contact between seal and upper seat $\left(3^{\text {rd }}\right.$ model).

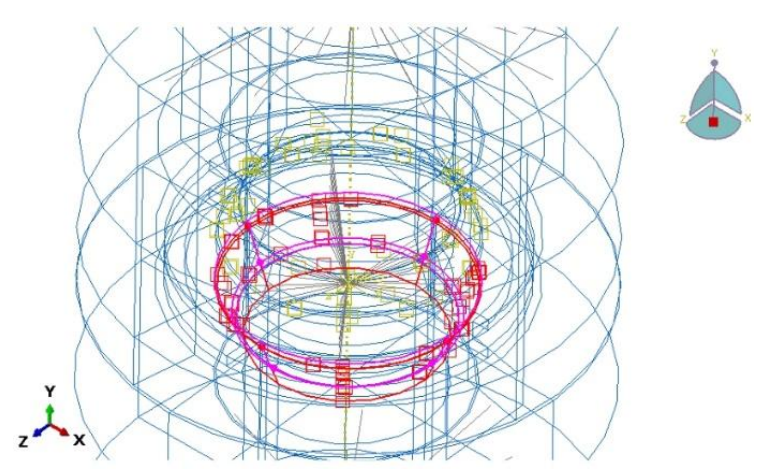

Figure 10. Contact between seal and lower seat $\left(3^{\text {rd }}\right.$ model). 


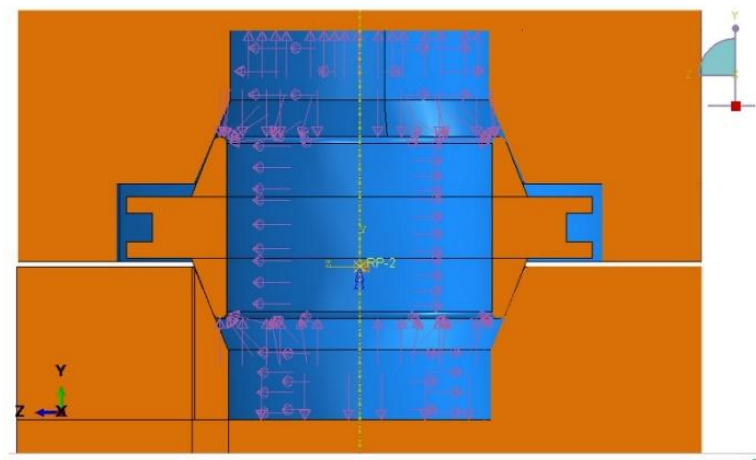

Figure 11. Internal pressure applied in model $\left(3^{\text {rd }}\right.$ model).

\section{RESULTS AND DISCUSSIONS}

After two steps, one could verify the following system results:

- Energization;

- Internal pressure application (final steps).

Verification after energization was checked because, generally, von Mises stress level achieved is higher in the final step. In addition, one can verify if, after energization, system showed reasonable values, which tend to remain reasonable after internal pressure step. Verification after the internal pressure is the most important stage in the process. With the results from the verification, it is possible to check if the design tends to maintain operating values with expected working conditions.

Following data were verified for each step:

- von Mises stress;

- Plastic strain;

- Contact pressure.

The von Mises stress is verified to check where and how seal had trespassed yield strength of material, and how close is tension from tensile strength. Plastic strain is checked to verify if and where a permanent deformation happened in the system after energization and application of internal work pressure. The most important result shown is contact pressure. It is checked to verify if system shows contact pressure between seal and seats at final model. Table 8 lists a summary of maximum values found for von Mises stress, plastic strain, and contact pressure in each model after first step.

From Table 8, result after system energization and before the application of internal pressure, it is possible to check that all models show contact pressure values which tend to answer with acceptable results for system sealing after the application of internal pressure. All values shown

Table 8. Results after energization step (maximum values).

\begin{tabular}{lccccc}
\hline \multicolumn{1}{c}{ Model } & \multicolumn{2}{c}{ von Mises Stress [MPa] } & \multicolumn{2}{c}{ Plastic Strain [\%] } & $\begin{array}{c}\text { Contact } \\
\text { Peal }\end{array}$ \\
& & Seat & Seal & Seat & Pressure [MPa] \\
\hline First & 408 & 444 & 9.17 & 5.06 & 150 \\
Second & 349 & 246 & 2.82 & - & 309 \\
Third (Final) & 344 & 385 & 2.53 & - & 650 \\
\hline
\end{tabular}

Table 9. Results after final step (maximum values).

\begin{tabular}{|c|c|c|c|c|c|}
\hline \multirow{2}{*}{ Model } & \multicolumn{2}{|c|}{ von Mises Stress [MPa] } & \multicolumn{2}{|c|}{ Plastic Strain [\%] } & \multirow{2}{*}{$\begin{array}{c}\text { Contact } \\
\text { Pressure [MPa] }\end{array}$} \\
\hline & Seal & Seat & Seal & Seat & \\
\hline First & 362 & 421 & 9.17 & 5.06 & 146 \\
\hline Second & 294 & 275 & 2.82 & - & 326 \\
\hline Third (Final) & 297 & 361 & 2.53 & - & 615 \\
\hline
\end{tabular}


are beyond expected internal pressure requested of $69 \mathrm{MPa}$. The first model showed a contact pressure value 2.2 times bigger than the expected internal pressure; the second model, 4.5 times; and the third model, 9.4 times.

Table 9 shows a summary of maximum values found for von Mises stress, plastic strain, and contact pressure in each model after the first step.

Results from Table 9 show that, for all models, contact pressure after system energization and application of internal pressure fulfil the basic premise to ensure system sealing. Once internal pressure required is $69 \mathrm{MPa}$, models show a sealing coefficient at order of 2.1 times greater for the first model, 4.7 for the second model, and 8.9 for the third model.
Figures 12, 13, 14, and 15 show, graphically, results for third model after the final step.

Figure 12 shows von Mises stress in the model. It is possible to check high tensions only next to upper and lower sealing band.

Figure 13 shows a permanent strain in the model. It is possible to check plastic strain only close to sealing area. Regions shown in dark blue, which represent the majority of the model, did not suffer permanent strain.

Figure 14 shows a contact pressure for upper and lower seats. Sealing bands are easily identified as regions from green to red colors. Regions identified in dark blue are regions without contact pressure.

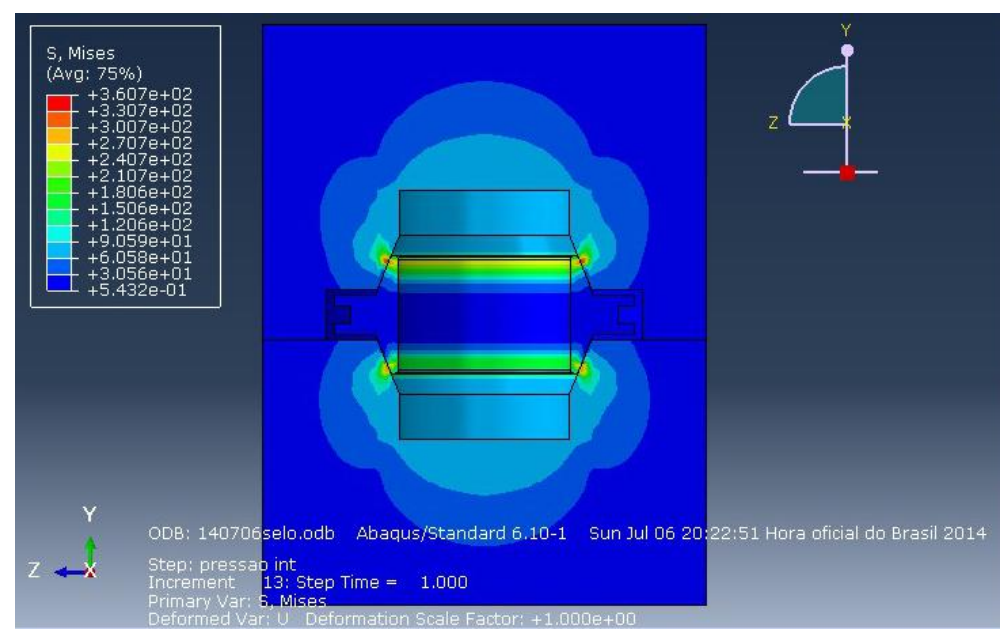

Figure 12. The von Mises stress in $3^{\text {rd }}$ model after final step [MPa].

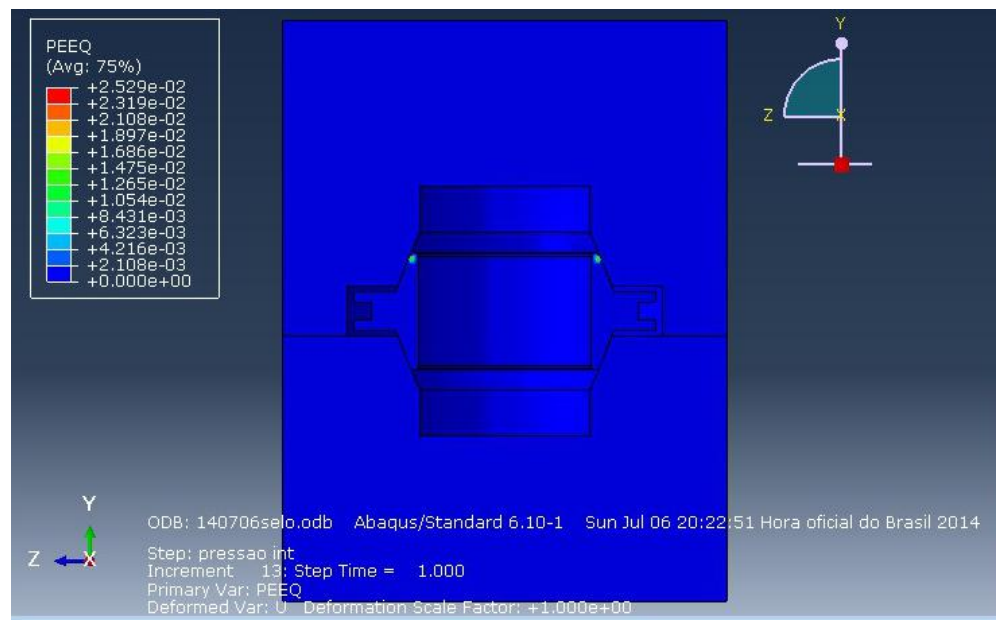

Figure 13. Plastic strain in $3^{\text {rd }}$ model after final step [\%]. 


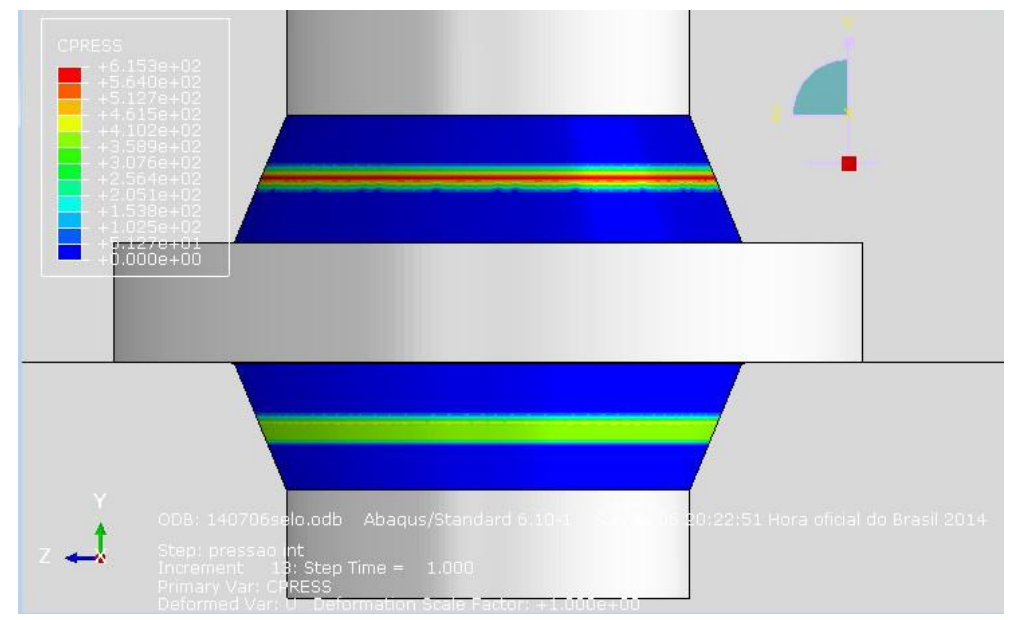

Figure 14. Contact pressure in $3^{\text {rd }}$ model at seats, after final step [MPa].

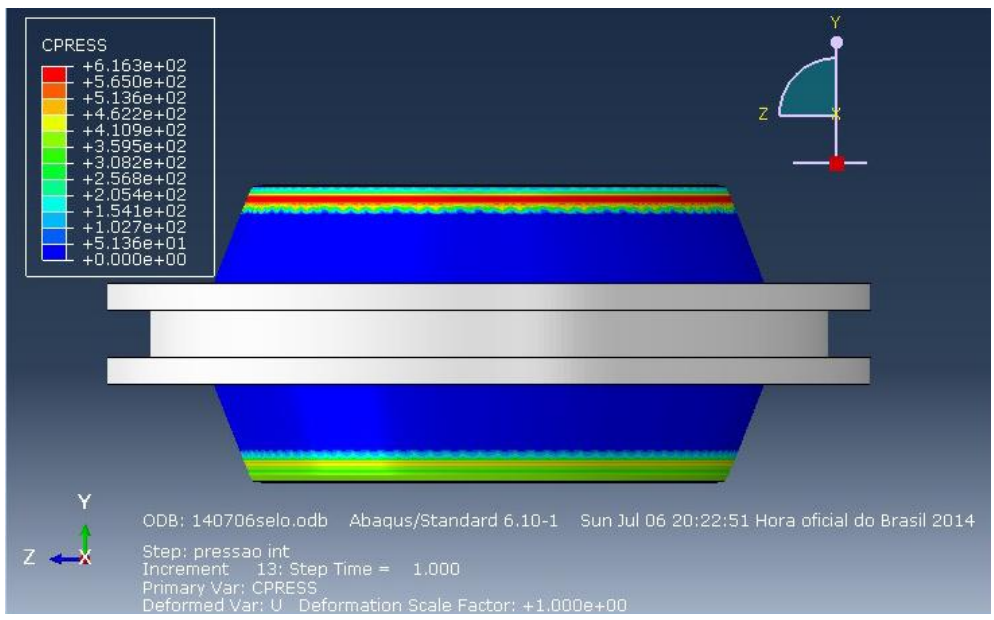

Figure 15. Contact pressure in $3^{\text {rd }}$ model in seal, after final step [MPa].

Figure 15 shows a contact pressure for the seal. Sealing bands are identified easily as regions from green to red color. Regions identified in dark blue are regions without contact pressure.

Beyond values of maximum von Mises stress achieved in each model, other important factor to check, visually, is which area of the seal trespassed yield strength of material.

Figures 16, 17, and 18 show von Mises stress for each seal in each model, filtered by yield strength of material.

Figure 16 shows the von Mises stress found in seal of first model after final step. Regions in grey show all regions that trespassed yield strength and worked in a plastic phase of material.

Figure 17 shows von Mises stress found in seal of second model after final step. Large regions are identified in red. These regions worked close to yield strength.

Figure 18 shows von Mises stress found in seal of third model after final step. Only regions close to sealing bands, identified in read, worked close to the yield strength.

All regions that trespassed yield strength are shown in grey. Comparing them, it is possible to check that first model shows a big portion of seal that trespassed the yield strength. Second model does not trespass yield strength, however, it shows a large portion of seal achieving high stress, close to yield strength. Third model shows a region with high level of tension only close to effective sealing area and it does not trespass the yield strength of material. 


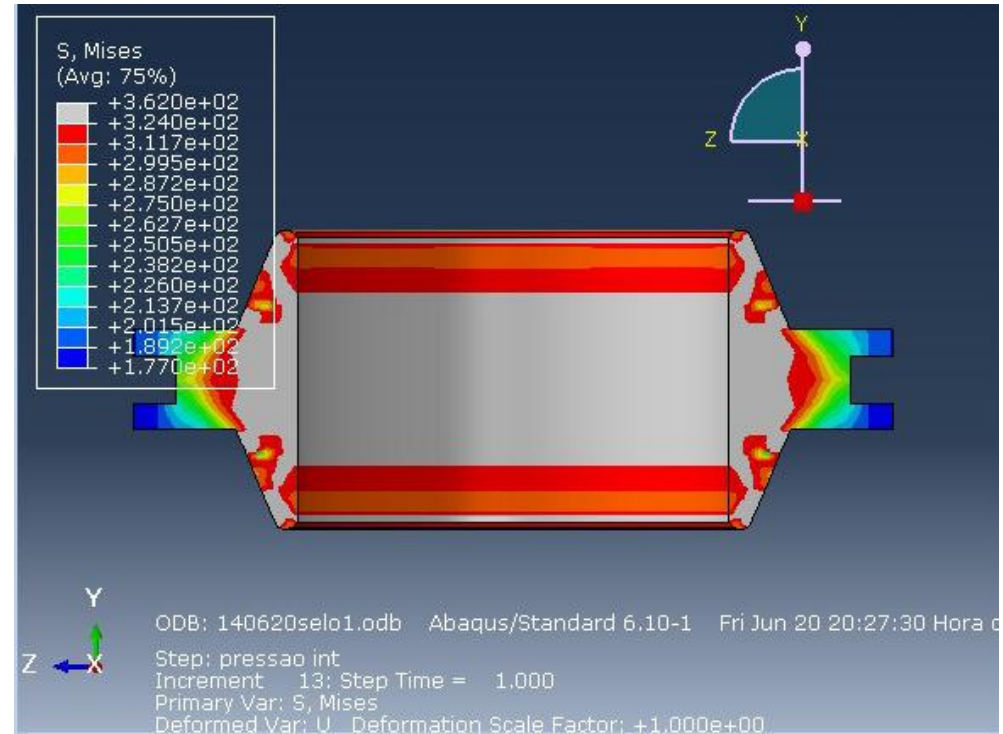

Figure 16. The von Mises stress in seal of $1^{\text {st }}$ model after final step [MPa].

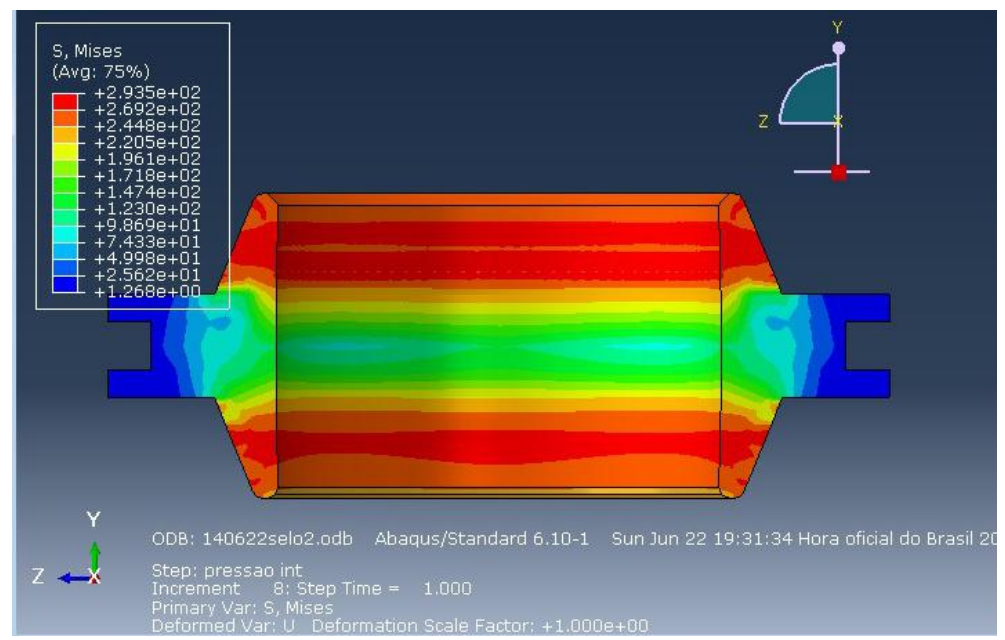

Figure 17. The von Mises stress in seal of $2^{\text {nd }}$ model after final step [MPa].

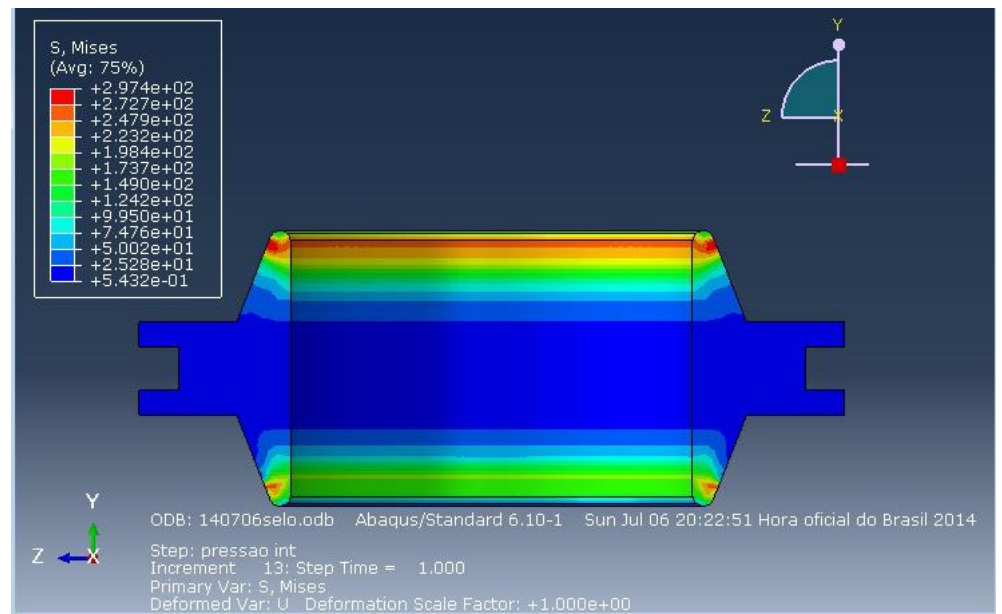

Figure 18. The von Mises stress in seal of $3^{\text {rd }}$ model after final step [MPa]. 
Evaluating results, it is possible to identify the effectiveness of the process when using finite element analysis to develop a metal-to-metal seal in an interactive way. After analyzing each model, it is possible to verify how the final result was modified by each change made model by model.

Comparing the models, it is possible to identify:

- In first model, result shows system capable to perform a sealing. However, sealing coefficient is low. Plastic deformation in seal is high and seal trespassed yield strength in a large area;

- Results for the second model show an improvement in sealing capacity. Plastic strain was reduced. However, seal presents high stress in areas distant from where sealing is performed;

- Results for the third model show an impressive improvement in sealing capacity. Plastic strain was reduced in value and it remained only in a region of seal which sealing was performed. In addition, seal generally presents lower stress; high stress appears only in areas close to the sealing region.

\subsection{Cost analysis}

This section presents a man hour cost comparison between qualification using FEA and validation test, and qualification using only validation test.

Qualification for metal-to-metal seal follows steps described by American Petroleum InstituteAPI (2011).

In this comparison, it is considered only manhours spend in each method mentioned. Since both processes can vary during execution, we only presented estimated numbers for each method.

Following steps are considered for FEA and validation test method:

- Design of seal;

- Calculation of seal $\left(1^{\text {st }}\right)$;

- Change of seal in accordance with analysis results $\left(1^{\text {st }}\right)$;

- Calculation of seal $\left(2^{\text {nd }}\right)$;

- Change of seal in accordance with analysis results $\left(2^{\text {nd }}\right)$;
- Calculation of seal $\left(3^{\text {rd }}\right)$;

- Validation test.

The following steps are considered for qualification using only the validation test method:

- Design of seal;

- Validation test;

- Change of seal in accordance with validation results $\left(1^{\text {st }}\right)$;

- Validation test $\left(2^{\text {nd }}\right)$;

- Change of seal in accordance with validation results $\left(2^{\text {nd }}\right)$;

- Validation test $\left(3^{\text {rd }}\right)$.

Considering the scenarios mentioned and estimating number of hours for each activity involving each type of specific professional, it is possible to make comparison shown in Table 10.

Table 10 shows estimated hours for each type of professional in each step of the test. Since validation test and FEA method for seal development are empiric methods, these numbers can vary.

According to Bai and Bai (2019), price of onshore service test engineer is around US\$1,000 US\$ 1,500 per day. Values for each professional shown in Table 11 are considered based on these numbers.

Table 11 considers a daily rate for an engineer based on a medium value mentioned in Bai and Bai (2019). Technician's rates are considered as half of this value. For hourly cost, it considered that professionals work eight hours per day.

Considering values mentioned in Table 11, estimated costs, based on labor per hour, are listed in Table 12.

Table 12 lists FEA and validation method costs below the validation method only.

Other costs were not mentioned in this cost analysis, i.e., extra costs for each real validation test repeated. Value for main device is still is same for both methods. Extra costs for new seals manufactured, consumables used, among other extra costs, were not computed. These real extra costs reinforce that the FEA method, and validation are less expensive than developing a seal using solely a validation test. 
Table 10. Work time estimated for FEA and validation test vs. qualification using only validation test.

\begin{tabular}{|c|c|c|c|}
\hline Step & Professional & $\begin{array}{l}\text { FEA and validation test } \\
\text { [h] }\end{array}$ & Validation test [h] \\
\hline Design of seal & Design engineer & 16 & 16 \\
\hline Calculation of seal $\left(1^{\text {st }}\right)$ & Analysis engineer & 40 & Not applicable \\
\hline $\begin{array}{l}\text { Change of seal in } \\
\text { accordance with analysis } \\
\text { results }\left(1^{\text {st }}\right)\end{array}$ & Design engineer & 8 & Not applicable \\
\hline Calculation of seal $\left(2^{\text {nd }}\right)$ & Analysis engineer & 24 & Not applicable \\
\hline $\begin{array}{l}\text { Change of seal in } \\
\text { accordance with analysis } \\
\text { results }\left(2^{\text {nd }}\right)\end{array}$ & Design engineer & 8 & Not applicable \\
\hline Calculation of seal $\left(3^{\text {rd }}\right)$ & Analysis engineer & 24 & Not applicable \\
\hline \multirow{2}{*}{ Validation test } & Test Engineer & 80 & 80 \\
\hline & Technician & 80 & 80 \\
\hline $\begin{array}{l}\text { Change of seal in } \\
\text { accordance with } \\
\text { validation results }\left(1^{\text {st }}\right)\end{array}$ & Design engineer & Not applicable & 8 \\
\hline \multirow{2}{*}{ Validation test $\left(2^{\text {nd }}\right)$} & Test Engineer & Not applicable & 80 \\
\hline & Technician & Not applicable & 80 \\
\hline $\begin{array}{l}\text { Change of seal in } \\
\text { accordance with } \\
\left.\text { validation results ( } 2^{\text {nd }}\right)\end{array}$ & Design engineer & Not applicable & 8 \\
\hline \multirow{2}{*}{ Validation test $\left(3^{\text {rd }}\right)$} & Test Engineer & Not applicable & 80 \\
\hline & Technician & Not applicable & 80 \\
\hline \multirow{4}{*}{ Total by professional } & Design engineer & 32 & 32 \\
\hline & Analysis engineer & 88 & Not applicable \\
\hline & Test engineer & 80 & 240 \\
\hline & Technician & 80 & 240 \\
\hline \multirow{2}{*}{$\begin{array}{l}\text { Total by professional } \\
\text { group }\end{array}$} & Engineer & 200 & 272 \\
\hline & Technician & 80 & 240 \\
\hline
\end{tabular}

Table 11. Cost estimation rate for type of professional.

\begin{tabular}{lll}
\hline Type of professional & Daily [US\$] & Hourly [US\$] \\
\hline Engineer & $1,250.00$ & 156.25 \\
Technician & 625.00 & 78.13 \\
\hline
\end{tabular}

Table 12. Estimated cost, based on labor-hour, for each method.

\begin{tabular}{ll}
\hline FEA and validation test [US\$] & Validation test [US\$] \\
\hline $37,500.00$ & $61,250.00$ \\
\hline
\end{tabular}

\section{CONCLUSIONS}

An analysis of the results shows that all seals demonstrated a capability to seal. After energization, all seals presented a contact pressure higher than that of the internal pressure applied. Using a finite element analysis during design, it was possible to improve the performance of seal on the most important points:
- Increasing a contact pressure, consequently increasing a sealing coefficient factor;

- Decreasing von Mises stress. It is desirable to work with lowest von Mises stress values as possible to avoid permanent strain and to increase the life of the sealing system;

- Decreasing regions with permanent strain, consequently, increasing life of sealing system. 
By improving the performance of seal through finite element method, the risk of failure during real validation test is reduced. Consequently, costs and time are reduced.

All seals presented the capability to seal. Using a finite element analysis as a process to improve the performance of seal can reduce number of times of real tests, consequently, saving costs in the development of a metal-to-metal sealing system.

\section{ACKNOWLEDGMENTS}

Dr. Wendell de Queiróz Lamas thanks his "Productivity Scholarship in Research," supported by the Brazilian National Council for Scientific and Technological Development (CNPq), grant number 300992/2018-1.

Dr. Francisco José Grandinetti thanks his "Productivity Scholarship in Technological Development and Innovative Extension," supported by the Brazilian National Council for Scientific and Technological Development (CNPq), grant number 313429/2019-7.

Dr. Giorgio Eugenio Oscare Giacaglia thanks his "Productivity Scholarship in Technological Development and Innovative Extension," supported by the Brazilian National Council for Scientific and Technological Development (CNPq), grant number 314689/2018-4.

\section{REFERENCES}

Abouel-Kasem, A. lifetime estimation and design of elastomeric seals with reinforced metal end caps. Sealing Technology, v. 2006(3), p.5-9, 2006. https://doi.org/10.1016/S1350-4789(06)71071-6

Alves Filho, A. Elementos Finitos - A Base da Tecnologia CAE. São Paulo, SP: Editora Érica, 2013.

American Petroleum Institute (API). API Specification 6A: Specification for wellhead and christmas tree equipment. $20^{\text {th }}$ Ed. Washington, DC: American Petroleum Institute, 2010.
American Petroleum Institute (API). API Specification 17D: Design and operation of subsea production systems-subsea wellhead and tree equipment. 2nd ed. Washington, DC: American Petroleum Institute (API), 2011.

Anderson, E. Nonlinear Finite Element Analysis and Seal Design Optimization. Salt Lake City, UT: Parker Hannifin Corporation, 1996.

Azevedo, A. F. M. Método dos elementos finitos. Porto: Universidade do Porto, 2003.

Bai, Y.; Bai, Q. (Editors). Subsea Engineering Handbook. $2^{\text {nd }}$ Ed. Houston, TX: Gulf Professional Publishing, 2019. https://doi.org/10.1016/B978-0-12812622-6.00001-4

Beer, F. P.; Johnston Junior, E. R.; DeWolf, J. T.; Mazurek, D. F. Mechanics of Materials. $7^{\text {th }}$ Ed. New York, NY: McGraw-Hill Education, 2014.

Bryant, M. J. Running-in and residual stress: Finite Element Contact Analysis of as Measured Rough Surfaces and Comparison with Experiment. PhD Thesis. Cardiff, CF: Cardiff University, 2013.

Callister Junior, W. D.; Rethwisch, D. G. Material Science and Engineering: An Introduction. $8^{\text {th }} \mathrm{Ed}$. New York, NY: John Wiley \& Sons, 2009.

Chen, Y.; Liang, T.; Peng, X.; Yu, H. Calculation and analysis of the first interface micro-gaps of the thermal production wells. Advances in Mechanical Engineering, v. 9(2), p. 1-9, 2017. https://doi.org/10.1177/1687814016688586

Cho, J. R.; Joo, B. D.; Cho, J. R.; Moon, Y. H. Finite element analysis of the offshore reel-laying operations for double-walled pipe. Advances in Mechanical Engineering, v. 9(10), p. 1-10, 2017. https://doi.org/10.1177/1687814017731226

Dassault Systèmes. Abaqus ${ }^{\circledR}$ Overview. 2015. Available at: http://www.3ds.com/productsservices/simulia/portfolio/abaqus/overview/.

Dassault Systèmes SIMULIA Corp. Enhanced FEA and simulation software reduces development time and costs. Sealing Technology, v. 2011(2), p. 4-5, 2011.

https://doi.org/10.1016/S1350-4789(11)70096-4 
Drill-Quip. Product Overview. Houston, TX: Drill-Quip, Inc. 2014. Available at: http://www.drilquip.com/ss15rld_subsea_wellhead.html.

Finney, R. H. Finite Element Analysis. In: Gent, A. N.; Ellul, M. D.; Finney, R. H.; Hamed, G. R.; Hertz, D. L.; James, F. O.; Lake, G. D.; Miller, T. S.; Campion, R. P. (Editors) Engineering with Rubber: How to Design Rubber Components, $3^{\text {rd }} \mathrm{Ed}$. Munich: Carls Hanser Verlag, p. 257-305, 2012. https://doi.org/10.3139/9783446428713.009

Flach, P. M. A seal is born. World Pumps, v. 351, p. 48-50, 1995 . https://doi.org/10.1016/S0262$\underline{1762(99) 81064-5}$

Flitney, R. K. Static Seals. In: Flitney, R. K. (editor). Seals and Sealing Handbook, $6^{\text {th }}$ Ed. Oxford, GB-OXF: Elsevier, p. 7-103, 2014. https://doi.org/10.1016/B978-0-08-099416-1.00002-4

Giner, E.; Sukumar, N.; Tarancón, J. E.; Fuenmayor, F. J. An abaqus implementation of the extended finite element method. Engineering Fracture Mechanics, v. 76(3), p. 347-68, 2009. https://doi.org/10.1016/i.engfracmech.2008.10.015

Haruyama, S.; Nurhadiyanto, D.; Choiron, M. A.; Kaminishi, K. Influence of surface roughness on leakage of new metal gasket. International Journal of Pressure Vessels and Piping, v. 111-112, p. 146154, 2013. https://doi.org/10.1016/i.ijpvp.2013.06.004

Hénap, G.; Szabó, L. On numerical solution of elastic-plastic problems by using configurational force driven adaptive methods. Finite Elements in Analysis and Design, v. 92, p. 50-59, 2014. https://doi.org/10.1016/j.finel.2014.08.002

Hou, M.; Su, M.; Liu, Y.; Gui, Z. Analysis of a dovetail o-ring groove performance. Sealing Technology, v. 8, p. 9-12, 2010.

https://doi.org/10.1016/S1350-4789(10)70393-7

Johnson, K. L. Contact Mechanics. Cambridge, GB-CAM: Cambridge University Press, 1987.

Jong, I. C.; Springer, W. Teaching von Mises Stress: From Principal Axis to Non-Principal Axis. Washington, DC: American Society for Engineering Education, 2009.

Kim, J.; Yoon, J.-C.; Kang, B.-S. Finite element analysis and modeling of structure with bolted joints. Applied Mathematical Modelling, v. 31(5), p. 895-911, 2007.

https://doi.org/10.1016/j.apm.2006.03.020
Klier, E.; Schäfer, F. EagleBurgmann supplies high-pressure seals for Russia's ESPO pipeline project. Sealing Technology, v. 2012(3), p. 10-12, 2012. https://doi.org/10.1016/S1350-4789(12)70101-0

Kossa, A.; Szabó, L. Numerical implementation of a novel accurate stress integration scheme of the von Mises elastoplasticity model with combined linear hardening. Finite Elements in Analysis and Design, v. 46(5), p. 391-400, 2010. https://doi.org/10.1016/i.finel.2009.12.006

Lin, T.; Yu, H.; Lian, Z.; Sun, B. Casing failure mechanism during volume fracturing: A case study of shale gas well. Advances in Mechanical Engineering, v. 9(8), p. 1-9, 2017.

https://doi.org/10.1177/1687814017717182

Luebkeman, C.; Peting, D. Stress-Strain Curves. Eugene, OR: University of Oregon. 1996. Available at:

http://pages.uoregon.edu/struct/courseware/461/ 461_lectures/461_lecture24/461_lecture24.html.

Natal Jorge, R. M.; Dinis, L. M. J. S. Teoria da Plasticidade. Porto: Faculdade de Engenharia, Departamento de Engenharia Mecânica e Gestão Industrial, Universidade do Porto, 2005.

Shi, J.; Chopp, D.; Lu, J.; Sukumar, N.; Belytschko, T.. Abaqus implementation of extended finite element method using a level set representation for three-dimensional fatigue crack growth and life predictions. Engineering Fracture Mechanics, v. 77(14), p. 2840-2863. 2010. https://doi.org/10.1016/i.engfracmech.2010.06.009

Slay, B.; Webber, W. Stress relaxation of elastomer compounds. Sealing Technology, v. 2011(2), p. 9-12, 2011.

https://doi.org/10.1016/S1350-4789(11)70108-8

Special Metals Corporation. Incoloy ${ }^{\circledR}$ Alloy 825. New Hartford, NY: Special Metals Corporation. $2004 . \quad$ Available at: http://www.pccforgedproducts.com/web/user_co ntent/files/wyman/Incoloy alloy 825.pdf.

Special Metals Corporation. Inconel ${ }^{\circledR}$ Alloy 625. New Hartford, NY: Special Metals Corporation. 2006. Available at: http://www.pccforgedproducts.com/web/user_co ntent/files/wyman/Inconel alloy 625.pdf. 
Sweeney, T. F.; Brammer, N.; Chalmers, G. Gasket with Multiple Sealing Surfaces. US 6772426 B2, issued 2004, 2004.

Trelleborg Sealing Solutions (TSS). Sealing Successful FEA. In the Groove, v. 28, p. 6-8, 2013. https://doi.org/10.1016/S1350-4789(13)70013-8

Woo, J. H.; Nam, J. H.; Ko, K. H. Development of a simulation method for the subsea production system. Journal of Computational Design and Engineering, v. 1(3), p. 173-186, 2014.

https://doi.org/10.7315/JCDE.2014.017

Yu, H.; Lian, Z.; Lin, T.; Liu, Y.; Xu, X. Experimental and numerical study on casing wear in highly deviated drilling for oil and gas. Advances in Mechanical Engineering, v. 8(7), p. 1-15, 2016. https://doi.org/10.1177/1687814016656535
Zhang, X.; Wang, G.; Xia, P.; Li, H.-P.; He, M. Finite element analysis and experimental study on contact pressure of hydraulic support bud-shaped composite sealing ring. Advances in Mechanical Engineering, v. 8(10), p. 1-9, 2016. https://doi.org/10.1177/1687814016674846

Zhao, C. Ultrasonic Motors: Technologies and Applications. Beijing: Springer, 2011.

https://doi.org/10.1007/978-3-642-15305-1 